\title{
Colonic schistosomiasis mimicking submucosal
}

\section{tumor}

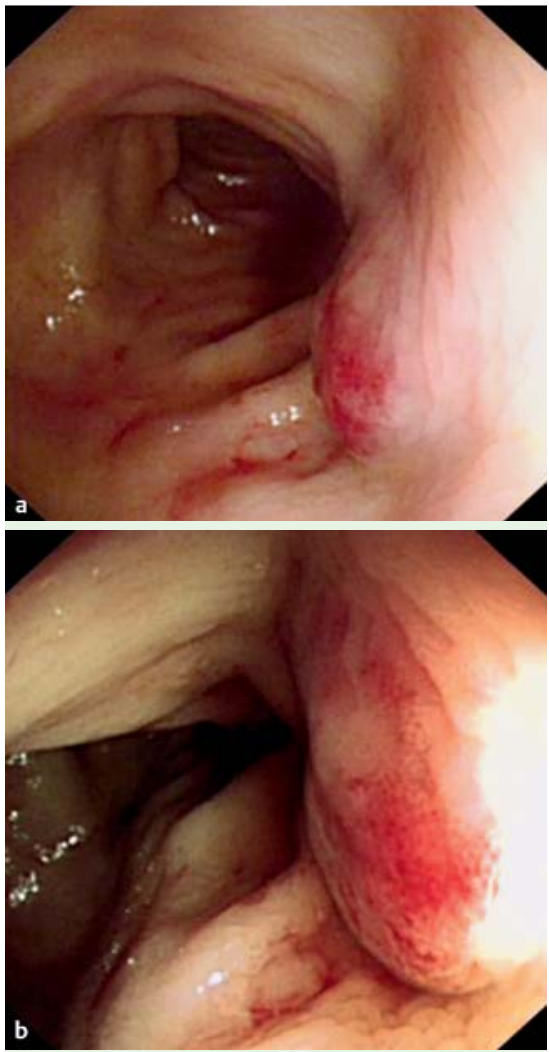

Fig. 1 a and b Colonoscopy revealed a submucosal tumor with congestive mucosa in the sigmoid colon.

The colonoscopic features of colonic schistosomiasis are variable. Here we report a rare case of colonic schistosomiasis mimicking submucosal tumor.

A 59-year-old man was admitted to our hospital complaining of intermittent melena and thinning stool. His symptoms had lasted for 5 years. He had lived in epidemic areas and was diagnosed with colonic schistosomiasis 20 years ago because of diarrhea, but he was cured and had regular follow-up for 3 years.

The physical examination showed no positive signs such as abdominal wall varicosis and spider angioma, apart from his facial features indicating mild anemia. Laboratory data showed hemoglobin $68 \mathrm{~g} / \mathrm{L}$, stool examination was negative for ova, and there were normal levels of tumor markers such as alpha-fetoprotein, carcinoembryonic antigen and carbohydrate antigen 19-9. The chest radiograph was normal. Abdominal computed tomography showed mild hepatic cirrhosis. The

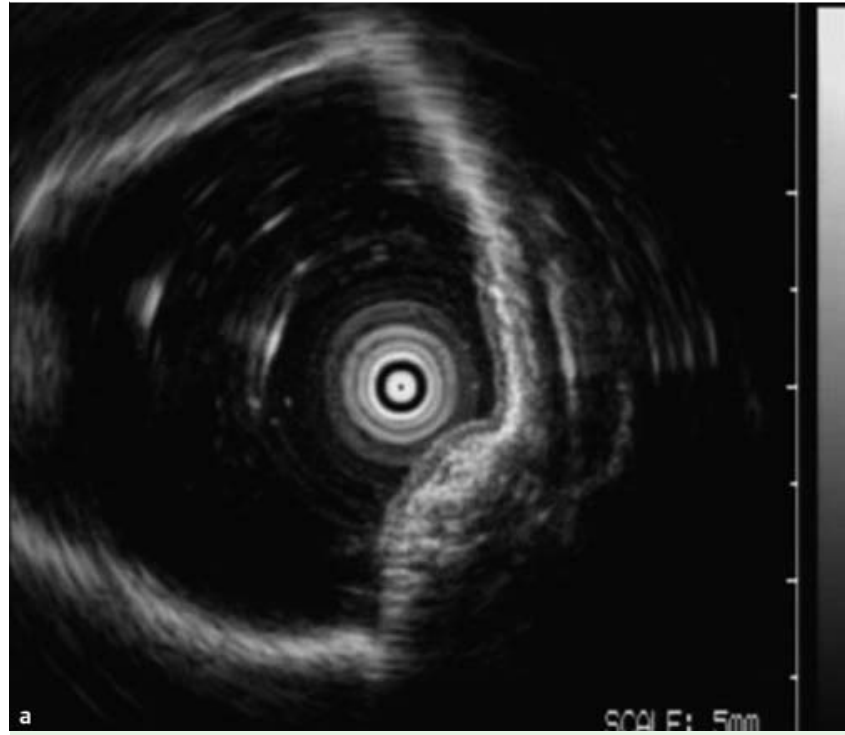

Fig. 2 a and b Endoscopic ultrasonography showed that the lesion originated from the submucosal layer and had multiple hyperechoic spots.
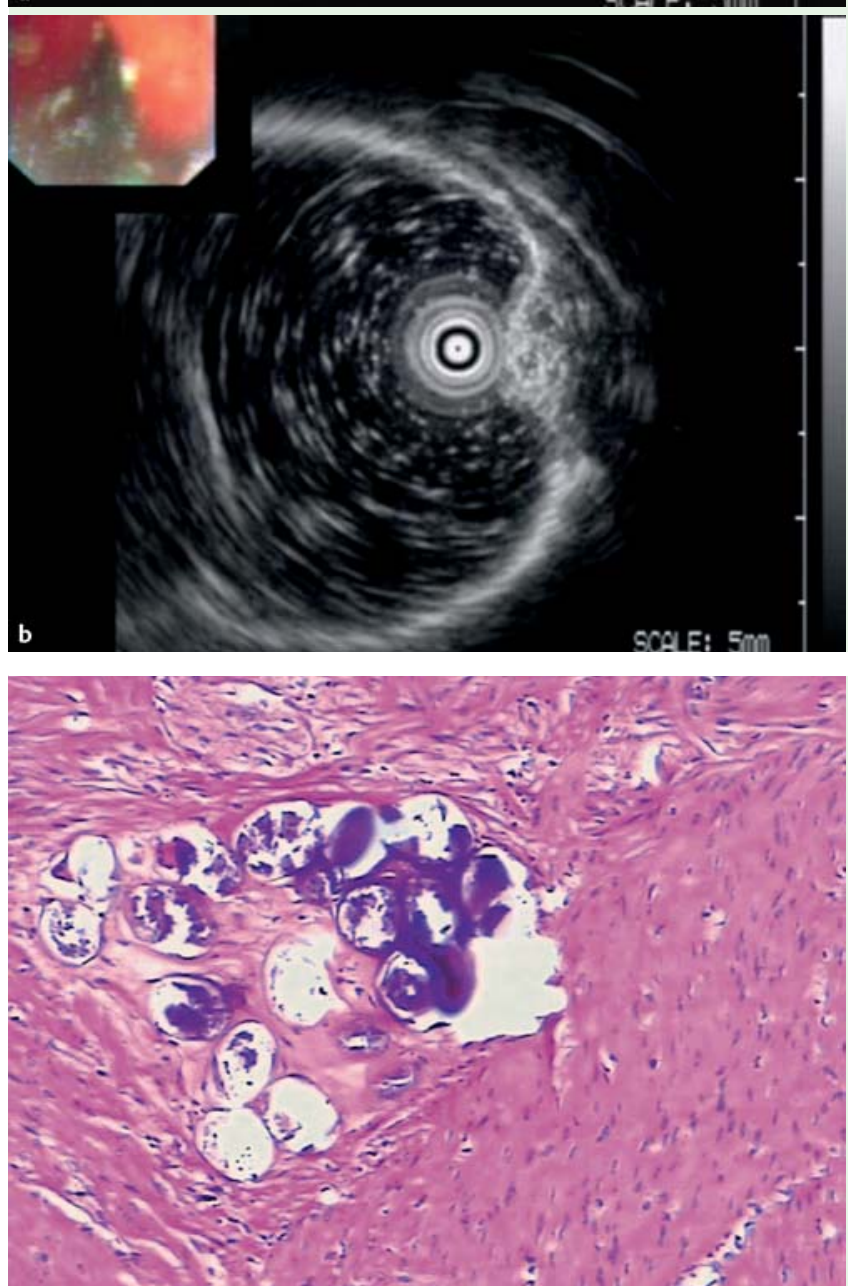

Fig. 3 Calcified schistosomal ova in the colonic wall. 
upper-gastrointestinal endoscopy did not show varices and ulcer, but the colonoscopy revealed a submucosal tumor with congestive mucosa in the sigmoid colon $(\bullet$ Fig. 1 a and $\mathbf{b}$ ).

Further endoscopic ultrasonography showed that the lesion originated from the submucosal layer and presented heterogeneous hypoechogenicity with multiple hyperechoic spots inside ( $\bullet$ Fig. 2 a and $\mathbf{b}$ ).

The patient worried that the lesion was malignant and accepted surgery. Histopathological examination of the specimen demonstrated many calcified schistosomal ova deposited in the colonic wall, mainly in the submucosa ( $\bullet$ Fig. 3 ).

Due to deposition of schistosomal ova in the submucosa producing a granulomatous reaction [1], colonoscopy in patients with schistosomiasis presents mucosal edema, hemorrhage, and ulceration at an acute stage, and a thickened bowel wall, flat or elevated nodules and polyps, or co- lonic stricture at a chronic stage [2]. Schistosomiasis mimicking submucosal tumor has not been reported before. Endoscopic ultrasonography (EUS) is a useful modality to diagnose submucosal tumors [3]. In this kind of case, a combination of previous history and EUS-guided fine needle aspiration (EUS-FNA) may help to make a correct judgment. Because of the potential for cancer, patients with colorectal schistosomiasis still need surveillance colonoscopy even after they have been successfully treated [4].

Endoscopy_UCTN_Code_CCL_1AD_2AJ

Competing interests: None

\section{Y. Q. Zhou, J. R. Huo, D. L. Liu,}

X. H. Wang, D. L. Ou

Department of Gastroenterology, Second Affiliated Hospital of XiangYa

Medical School, Central South University, Changsha, China

\section{References}

1 Yosry A. Schistosomiasis and neoplasia. Contrib Microbiol 2006; 13: 81 - 100

2 Ohmae H, Sy OS, Chigusa Y, Portillo GP. Imaging diagnosis of schistosomiasis japonica the use in Japan and application for field study in the present endemic area. Parasitol Int 2003; 52: $385-393$

3 Chak A. EUS in submucosal tumors. Gastrointest Endosc 2002; 56: S43-S48

4 Konishi T, Watanabe T, Shibahara J, Nagawa $H$. Surveillance colonoscopy should be conducted in patients with colorectal Shistosomiasis even after successful treatment of the disease. Int J Immunopathol Pharmacol 2006; 19: 245-246

Bibliography

DOI $10.1055 / \mathrm{s}-0030-1256078$

Endoscopy 2011; 43: E58 - E59

(c) Georg Thieme Verlag KG Stuttgart - New York . ISSN 0013-726X

Corresponding author

\section{Y. Q. Zhou, MD}

Department of Gastroenterology

Second Affiliated Hospital of XiangYa Medical

School

Changsha, 410010

Hunan, China

yuqz333@126.com 